\title{
Use of E18 Cell Model to Quantify DNA Strand Break Associated Bystander Effect (DSB-ABE)
}

\section{Jalal Nasir*}

School of Pharmaceutical Science and Technology, Tianjin University, 92 Weijin Road, Tianjin, P.R. China

\begin{abstract}
The lymphoblast cell line E18 is a derivative of TK6 and has an I-Sce1 insert in the intron 2 of heterozygous TK1/ tk1 gene. E18 can be targeted with I-Sce1 restriction endonuclease to induce double strand breaks at the I-Sce1 site to measure radiation independent DNA damage and the associated bystander effect. For construction of E18 cell line an Eco47III site was inserted into the pTK-UAS linearized plasmid backbone and annealed with blunt-ended oligonucleotides of ISce1 restriction sequence in the presence of DNA ligase. DH5- $\alpha$ cells were transformed by heat transfecting the cells with pTK-UAS-Eco47III-Sce1 and selecting ampicillin resistant colonies. Plasmid DNA was extracted and analyzed for the presence of Eco47III and I-Sce1 sites. A clone with I-Sce site in intron 2 of the thymidine kinase active allele was selected for further experimentation and named E18. This model was tested to demonstrate the double strand break induced mutations and these strand breaks can also produce DNA strand break associated bystander effect (DSB-ABE) as measured by increased mutation frequency in naïve cells. The plasmid pAdTrackCMV I-Sce1 carrying GFP marker was electroporated in E18 cells to express the I-Sce1 restriction endonuclease which specifically targets the I-Sce1 site at intron 2 of the active TK allele. Mutation fraction assay was employed to measure direct mutation fraction (DMF) or accompanied by conditioned medium transfer to naïve cells for measuring bystander mutation fraction (BMF) as an end-point of targeting E18 with an exogenous I-Sce1 expression via pAdTrackCMV I-Sce1 to induce DNA damage and quantify DMF and BMF.
\end{abstract}

Keywords: DNA damage; DNA repair; Bystander effect; Mutation fraction; Cell model

\section{Introduction}

More than 600 chromosomal aberrations have been identified in neoplastic cells and almost 100 genes found to be involved in neoplasia related chromosomal rearrangements [1]. Most characterized chromosomal rearrangements can exert their action by two potential mechanisms, i.e., over expression of a normal gene at the break point or creation of a hybrid gene through fusion of two parts of two separate genes. Double strand breaks (DSBs) are by far one of the most deleterious in terms of their susceptibility to development of a protumorigenic genotype [2]. Failure to repair DSBs or defective repair may be mutagenic, or even lethal to the cell, and may cause genetic defects that lead to genetic diseases and cancer [3]. The observation of tumor specific defects in the DNA damage response has provided investigators with an opportunity to look for cancer specific therapies [4,5].

In recent years radiation-induced DNA damage has been linked to the release of a soluble cell signal into the surrounding medium that can cause genetic aberrations in naïve non-targeted cells [6]. This phenomenon had been referred to as radiation induced bystander effect (RIBE) [7,8]. And describes an effect in which cells that are not directly exposed to ionizing radiation behave as if they have been exposed by exhibiting effects of direct exposure such as apoptosis or genomic instability. Using precision micro beams, low-dose internal radiation $\beta$-particles and hadron radiations, various investigators were able to find out several end-points and effects of bystander signaling in naïve mammalian cells. These include but are not limited to genetic and epigenetic transformations that according to some estimates were previously underestimated [9], genomic instability [10] which can cause lethal mutations and altered gene expression [11], activation of several signal transduction pathways in a dose dependent manner $[6,12,13], \gamma-\mathrm{H}_{2} \mathrm{AX}$ foci formation [14], delayed apoptosis [1,15-17], sister chromatid exchanges (SCE) [6,18], micronucleation $[17,19]$ and neoplastic transformations [11].
For almost two decades bystander effects have been widely linked to DNA damage by radiation but DNA damage is not unique to just ionizing radiation [20] but have also been demonstrated through the use of chemotherapeutic drugs [21] and photodynamic stress agents [22]. It is known that in attached cells the bystander signal is transmitted through gap junctions and in suspension cells this happens via soluble factors released into the medium [23] and that bystander signals could be detected in the medium for up to $24 \mathrm{~h}$ after radiation exposure.

I-Sce1 endonuclease is a mitochondrial intron-encoded endonuclease of Saccharomyces cerevisiae which has a very low probability of cutting the DNA even within large genomes. It was demonstrated by some investigators $[24,25]$ that double strand breaks can be initiated by I-Sce1 at pre-determined location in a mammalian genome. It was also argued that non-nuclear targets in the cytoplasm can also produce bystander effects after irradiation $[14,26]$.

At this point of bifurcation in the concept of bystander effect it is necessary to investigate if radiation independent DNA damage would also produce bystander effect. To test this hypothesis we constructed a cell line by introducing the yeast I-Scel restriction site into the active allele of the heterozygous TK1 gene in human TK6 cells. The 18 base pair recognition sequence does not exist normally in the human genome. Expression of I-Sce1 endonuclease will therefore induce only one double strand break at a specific site in the tk. This system mimics

*Corresponding author: Jalal Nasir, School of Pharmaceutical Science and Technology, Tianjin University, 92 Weijin Road, Tianjin, P.R. China, Tel: +8615510951246; E-mail: nasirjalal@tju.edu.cn

Received May 01, 2017; Accepted June 07, 2017; Published June 12, 2017

Citation: Nasir J (2017) Use of E18 Cell Model to Quantify DNA Strand Break Associated Bystander Effect (DSB-ABE). J Carcinogene Mutagene 8: 295. doi: 10.4172/2157-2518.1000295

Copyright: (c) 2017 Nasir J. This is an open-access article distributed under the terms of the Creative Commons Attribution License, which permits unrestricted use, distribution, and reproduction in any medium, provided the original author and source are credited. 
the radiation dependent DNA damage that has previously been linked to bystander mutation in naïve cells. A similar cell line using I-Sce1 insert in intron 4 was constructed previously by other investigators to identify the relative contribution of DNA repair using the two dominant DNA repair pathways of non-homologous end-joining (NHEJ) and homologous recombination (HR) [27-29].

Thymidine kinase gene can be used as a selectable marker for mutations ranging from point to megabase deletions, besides recombination events can be studied using the tk heterozygous cell line TK6 [30,31]. The construction of the cell line, reported here, began with the use of TX528 cells [32] which is derived from TK6 lymphoblasts, an immortalized cell line characterized by Giver et al. [33].

This cell model and similar I-Scel based system can be used for various purposes, some of which may include: comparing DNA repair via non homologous end-joining or homologous recombination [25,27] or their dependence on cell cycle [28,29]. I-Sce1 has also recently been used to develop a gene drive system in embryos to selectively eradicate malaria causing mosquito populations [34].

The strength of this model is to induce one site specific DNA double strand break. We used this strength to demonstrate that double strand breaks induced in directly targeted cells can increase the mutation fraction in naïve E18 cells upon transfer of conditioned medium from direct to naïve cells. Since I-Sce1 has an 18 base recognition sequence it is highly unlikely that the human genome can express a similar sequence elsewhere. This system, in so doing, mimics the lowest possible radiation damage a cell could receive.

\section{Materials and Methods}

\section{Vectors}

Plasmid pTK-UAS was used as a targeting vector. In the first step an oligonucleotide carrying Eco47III site was linearized with FspI (NEB cat \# R0135S) having the restriction sequence $5>\mathrm{TGC}^{\vee} \mathrm{CGA}>3$ and allowed to anneal with an 18 base pair $(\mathrm{bp})$ recognition sequence of I-Scel (5' TAGGGATAA ${ }^{\vee C A G G T A A T ~} 3^{\prime}$ ) and the resultant vector called pTKUAS-Eco47III-Sce. Disruption of intron 2 of TK6 cells was then carried out by non-targeted mutagenesis dependent on electroporation of this modified vector into TX528 cells. DNA extract from clones was tested for transfectants carrying the Eco47III site by running cleaved and uncleaved PCR products on a $2 \%$ agarose gel. The product showing Eco47III site was gel purified (using Qiagen kit).

\section{Ligation and transformation}

A 3:1 molar ratio of I-Sce1 insert to pTK-UAS-Eco47III vector was used. Quick Ligation kit (NEB) was used to ligate and insert the vector into host cells. Transformation was carried out using Max-efficiency competent DH5a cells from Invitrogen using the protocol provided by vendor, briefly $(50 \mu \mathrm{L}$ cells $+15 \mathrm{ng}$ DNA from ligation were mixed together in $950 \mu \mathrm{L}$ of Laurel's broth medium (LBM)+ampicillin, shaken for $80 \mathrm{~min}$ at $255 \mathrm{RPM}$ and $\left.37^{\circ} \mathrm{C}\right)$. Transformed cells $(200 \mu \mathrm{L})$ were cultured on Laurel broth agar+ampicillin plates overnight at $37^{\circ} \mathrm{C}$. Next day the ampicillin resistant clones were picked up and grown in $250 \mathrm{~mL}$ of LBM+ampicillin for another $12-16 \mathrm{~h}$ at $37^{\circ} \mathrm{C}$ and $225 \mathrm{RPM}$ in a 500 $\mathrm{mL}$ flask. The plasmid DNA was then extracted using Qiagen miniprep spin kit, using vendor provided protocol.

\section{Cell construction}

TK6 human lymphoblastoid cells are heterozygous for a point mutation in exon 4 of the TK gene. They were grown in RPMI 1640 medium (Gibco, Carlsbad CA), supplemented with $10 \%$ heat inactivated horse serum. TK deficient clones were generated by transfecting TK6 cells with the linearized targeting vector pTKUAS-Eco47III-Sce. TK6 cells were grown to a density of $1 \times 10^{6}$ cells $/ \mathrm{mL}$ and resuspended at 20 x $10^{6}$ cells $/ \mathrm{mL}$ in electroporation buffer to prepare a $250 \mu \mathrm{L}$ reaction containing $5 \mu \mathrm{g}$ of linearized vector DNA and electroporated in a $4 \mathrm{~mm}$ gap cuvette at $250 \mathrm{~V}, 960 \mu \mathrm{F}$ using a BioRad pulse generator. After 72 $\mathrm{h}$ the cells were plated in a 96 well plate in the presence of $2.0 \mu \mathrm{g} / \mathrm{mL}$ trifluorothymidine (TFT). TK deficient clones were selected by TFT on day 20 , as described earlier $[34,35]$. One of the clones was found to carry the desired vector with the Eco47III site along with the I-Sce1 recognition sequence and we called it E18 (Figure 3).

\section{Detection of I-Sce1 site within the TK locus}

The plasmid DNA was digested with Eco 47III enzyme first and later with 50 units of I-Scel enzyme and ran on a $2 \%$ agarose gel to confirm the presence of both sites. TX 528 cells were electroporated with pTK-UAS containing the I-Scel insert in the Eco47III site. After transfection, $2 \times 10^{7}$ TX528 cells with $50 \mu \mathrm{g}$ Fsp1 digested plasmid DNA was added to $30 \mathrm{~mL}$ of RPMI (supplemented with horse serum and PenStrep). Two days later 10,000 cell/well were plated into 96 well plates. Positive clones were picked up at 8-12 days post-transfection. 20 Clones with Eco47III site were stored in $-80^{\circ} \mathrm{C}$ freezer for a short time.

\section{Primers}

Since we used thymidine kinase 1 as the gene of interest, therefore only those clones were targeted that received I-Scel insert within the introns of TK1 gene. Primers were designed for Eco47III site to detect the presence of Eco47III site within the TK1 gene. Primers used were 1541F (5'-CCT GCC CCA ACA TTC TTT TA-3') and 1763R (5'-TCA AGT GAT CAA CGC ACC TC-3') and the resulting product was $223 \mathrm{bp}$. The control cell line used was TK6 and the modified TX528 clone with Eco47III site+I-Sce1 insert was called E18, \#18 refers to the clone that demonstrated the desired traits (Figure 3). If I-Sce1 enzyme is transfected into these cells, one and only one double strand break should be generated. For exogenous expression of I-Sce1 enzyme, we used electroporation to transfect the plasmid (pAdTrack CMV I-Sce1) containing the gene.

\section{Plasmid used for exogenous expression of I-Sce1}

The experimental plasmid pAdTrackCMV I-Scel used in this research was acquired from Dr. Jac Nickoloff's laboratory at Colorado State University while the control plasmid pAdTrackCMV was purchased from Addgene Inc., (cat\# 16405 mammalian plasmid). They were both grown in E. Coli DH5a cells, cultured in Kanamycin supplemented LB broth respectively and sub-cultured in LB agarose plates also supplemented with Kanamycin for $16 \mathrm{~h}$. Plasmid DNA was extracted with Qiagen's miniprep spin kit (Cat \# 27104). Control plasmid pUC 19 was also used for some experiments to offset the mutational changes otherwise associated with huge GFP marker in the other two plasmids.

\section{Electroporation parameters for lymphoblastoid cells}

The cells were thawed in RPMI 1640 complete growth medium (10\% Horse serum and 1\% PenStrep). The cells were passaged for 3-4 days in a non-antibiotic supplemented medium to avoid any additional stress on the culture prior to electroporation. They were grown to a density of $1 \times 10^{6}$ cells $/ \mathrm{mL}$ but never allowed to go past that density to prevent contact inhibition. The cells were pelleted by spinning at 1000 rpm for 5 minutes and re suspended in electroporation buffer to get a 


\begin{tabular}{|c|c|}
\hline Cell density $5 \times 10^{6}$ cells $/ 250 \mu \mathrm{L}$ or $20 \times 10^{6}$ cells $/ \mathrm{mL}$ & Voltage: $250 \mathrm{~V}$ \\
\hline Volume for reaction mixture: $250 \mu \mathrm{L}$ & Field strength: $0.625 \mathrm{kV} / \mathrm{cm}$ \\
\hline DNA concentration $10-25 \mu \mathrm{g} /$ pulse/reaction & Capacitor: $960 \mu \mathrm{F}$ \\
\hline Cuvette gap: $4 \mathrm{~mm}$ & Time constant: $60 \mathrm{~m} / \mathrm{sec}$ \\
\hline
\end{tabular}

Table 1: Parameters for electroporation in a BioRad gene pulser.

total density of $5 \times 10^{6}$ cells $/ 250 \mu \mathrm{L}$ of electroporation buffer to prepare the stock for reaction mixture. Measured 10-25 $\mu \mathrm{g}$ of total plasmid DNA extracted from the E. Coli DH5a cells (DNA extraction was performed using Plasmid Miniprep kit from Promega). Each electroporation reaction was set up using 10-25 $\mu \mathrm{g}$ of total Plasmid DNA added to a $1.5 \mathrm{~mL}$ of sterilized Eppendorf tube and then added with $250 \mu \mathrm{L}$ of cells resuspended in electroporation buffer. Following settings were used for the BioRad Gene Pulser, as specified by the vendor (Table 1).

Immediately after electroporation the cells were immersed into warm, fresh RPMI 1640 medium (supplemented with 10\% Horse serum and $1 \%$ PenStrep) and incubated at $37^{\circ} \mathrm{C}$ for $5 \mathrm{~h}$ to get 50 $70 \%$ electroporation efficiency. Cell viability in post-electroporation conditions was approximately $90-95 \%$.

\section{Recipe for the Electroporation buffer (For $1 \mathrm{~L}$ buffer)}

The recipe for electroporation buffer comprised: $\mathrm{NaCl} 8 \mathrm{~g}$, $\mathrm{Na}_{2} \mathrm{HPO}_{4} .7 \mathrm{H}_{2} \mathrm{O}_{2} .16 \mathrm{~g}, \mathrm{KCl} 0.2 \mathrm{~g}, \mathrm{KH}_{2} \mathrm{PO}_{4} 0.2 \mathrm{~g}$, were dissolved in 800 $\mathrm{ml} \mathrm{ddH} \mathrm{H}_{2} \mathrm{O}$ and $\mathrm{pH}$ adjusted to 7.3. A final volume of $1000 \mathrm{ml}$ was made up with $\mathrm{ddH}_{2} \mathrm{O}$ and filtered using a $2.0 \mu \mathrm{m}$ pore sized filter.

\section{Lipofection (as per vendor protocol)}

Transfection reagent marketed by Mirus ${ }^{\oplus}$ and specifically called the Mirus TransIT 2020 reagent was used for lipofection. E18 cells were grown to $1 \times 10^{6} \mathrm{c} / \mathrm{mL}$ and incubated at $37^{\circ} \mathrm{C}$. A $2.5 \mathrm{~mL}$ aliquot of this culture medium was added per well to a 6 well plate and incubated for 18-24 h. Lipofection mixture was prepared by mixing TransIT2020 (Mirus reagent) with plasmid DNA to prepare the DNA complex. The reaction mixture was prepared by adding $250 \mu \mathrm{L}$ of OptiMEM I reduced serum medium in a sterile polystyrene tube and gently adding $2.5 \mu \mathrm{g} /$ $\mu \mathrm{L}$ of plasmid DNA to the tube. A $7.5 \mu \mathrm{L}$ of TransIT2020 reagent was added to the reaction mixture and incubated at room temperature for 15-30 minutes to allow the micelles to develop. A $43 \mu \mathrm{L}$ aliquot of this transfection mixture was added to a $1 \mathrm{~mL}$ eppendorf tube containing E18 cells at a density of $1 \times 10^{6} \mathrm{c} / \mathrm{mL}$. The cells were allowed incubation with the transfection mixture for up to $72 \mathrm{~h}$ and harvested to establish transfection efficiency.

\section{Transfection efficiency}

Transfected cells were fixed on a glass slide using Carnoy's fixative and allowed to air dry for $24 \mathrm{~h}$ in dark. The slides were then counterstained with DAPI and viewed at X 100 under the FITC and DAPI channels of UV illuminated microscope. At least five fields of view were randomly chosen to count the number of cells that showed green fluorescence (from GFP marker) as positively transfected cells. The transfection efficiency was calculated using the formula:

Transfection efficiency (TE\%)=average of total number of green cells in 5 random fields of view x 100/average of total number of cells per view.

\section{Mutation assay (adapted from Liber and Thilly)}

E18 human lymphoblasts are thymidine kinase heterozygotes $(\mathrm{TK}+/-)$, and therefore mutations at this locus $(\mathrm{TK}+/-\rightarrow$ tk-/-) can be easily quantified by selecting cells in the pyrimidine analog trifluorothymidine (TFT). For direct and bystander studies the cells were incubated at $37^{\circ} \mathrm{C}$ and $5 \% \mathrm{CO}_{2}$ for $5 \mathrm{~h}$ after electroporation to generate a bystander signal and the medium was later transferred to naïve cells which were in turn incubated for $72 \mathrm{~h}$ to allow the appearance of mutant cells within the naïve ones [35]. Following 72 $\mathrm{h}$ incubation after electroporating $1 \times 10^{5} \mathrm{cells} / \mathrm{ml}$ the lymphoblastoid cells were plated in 96 well plates at 20,000 cells per well in the presence of TFT to isolate mutants (mutant fraction MF) and at 1 cell per well to determine the plating efficiency (PE). Twelve days after seeding, the PE plates were counted for positive wells with colonies while MF plates were re-fed with TFT. At 20 days post-plating the MF plates were counted for positive wells with colonies. Both MF and PE plates were used in duplicates to reduce error. Mutant fractions were determined using the general formula for Poisson distribution given as under.

$$
\operatorname{Pr}(\lambda)=\frac{\lambda^{n} e^{-\lambda}}{n !}
$$

$\mathrm{n}=\#$ of events, $\lambda=$ frequency of events

$$
\begin{aligned}
& \text { PE was calculated as: } \frac{\ln (\text { fraction of negative wells })}{\text { Number of cells seeded / well }} \\
& \text { MF was calculated as: } \frac{P E \text { for mutation plates }}{P E \text { for non-selective plates }}
\end{aligned}
$$

\section{Statistical analysis}

Statistical analysis was carried out using the program Graphpad Prism 5 (GraphPad Software, Inc., La Jolla, CA 92037 USA). All experimental data was replicated at least three times. All groups were tested for significance by either one way or two ways ANOVA.

\section{Results}

\section{Construction of E18 cell line}

TX528 lymphoblast cell line was a gift from AJ Grosovsky (U.C. Riverside, now at U. Mass., Boston). These cells have a 9 base pair deletion in exon 1 of the active allele and frame shift mutation in exon 4 of the inactive allele and derived from the TK6 cell line [32]. We used the pTK-UAS backbone to build a targeting vector that would carry an I-Sce1 insert in the BsrG1, BamH1, Eco47III and BsrG1+BamH1 sites. We explain only the clones that were obtained from using the Eco47III site. Details of the process are enlisted in the materials and method section. The plasmid pTK-UAS-Sce-Eco47III was used to transform Max-efficiency DH5- $\alpha$ bacterial cells grown in LBM with ampicillin and resistant clones picked up for further expansion in ampicillin-containing agar plates. Figure 1 shows the location of Eco47III within the pTK-UAS backbone. Since our targeting vectors included genomic DNA only through exon 3, they did not correct the exon 4 frameshift in the inactive $t k$ allele but they could correct the exon 1 deletion, leading to loss of heterozygosity (LOH). The mutants were isolated using an established method [36-39]. Plasmid DNA from the transformed bacterial cells was extracted and this plasmid DNA was cut with BamH1, BsrG1, Eco47III or BamH1+BsrG1 enzymes. The positive clones for each site were selected and used for further investigations. A number of these clones were then used to locate the I-Scel site within each of the above-mentioned sites. Figure 2 shows the identification of I-Sce1 site at Eco47III and BsrG1 sites. Out of the 20 Eco47III clones, nine were selected for further analysis (Figure 3). These clones were grown in CHAT supplemented RPMI 1640 medium and plated in 96 well plates. The resistant clones were used for DNA extraction and polymerization, using primers that gave a PCR product of $223 \mathrm{bp}$. This DNA was then digested with 50 units of I-Scel enzyme 
Citation: Nasir J (2017) Use of E18 Cell Model to Quantify DNA Strand Break Associated Bystander Effect (DSB-ABE). J Carcinogene Mutagene 8: 295. doi: $10.4172 / 2157-2518.1000295$

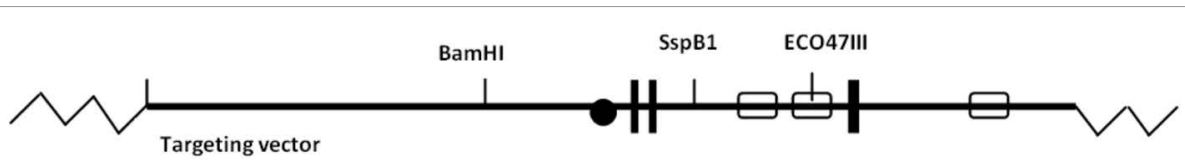

\begin{tabular}{llllllll}
1 & & & & & & \\
\hline-4.2 & -1.3 & -0.5 & 0 & 0.4 & 1.6 & $3.1 \mathrm{~kb}$
\end{tabular}

Figure 1: pTK-UAS vector with BamH1 and Eco47III sites.

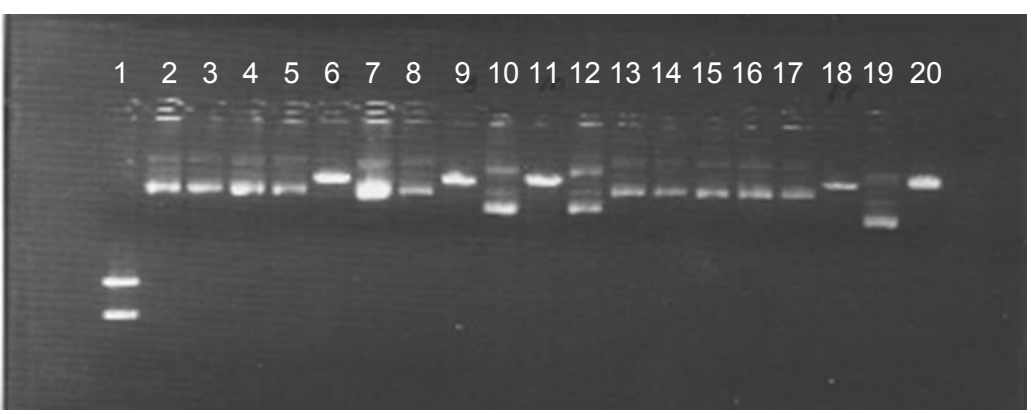

Figure 2: I-Scel digest of selected clones. Molecular weight marker in lane 1, I-Scel substrate in lanes 2-20 comprises transformed clones of Scel, 6 , 9, 18. Positive clones for Scel site at Eco47III, 11. Positive for I-Scel site at BsrG I, 19. Linearized p5'TK- UAS in lane 20.

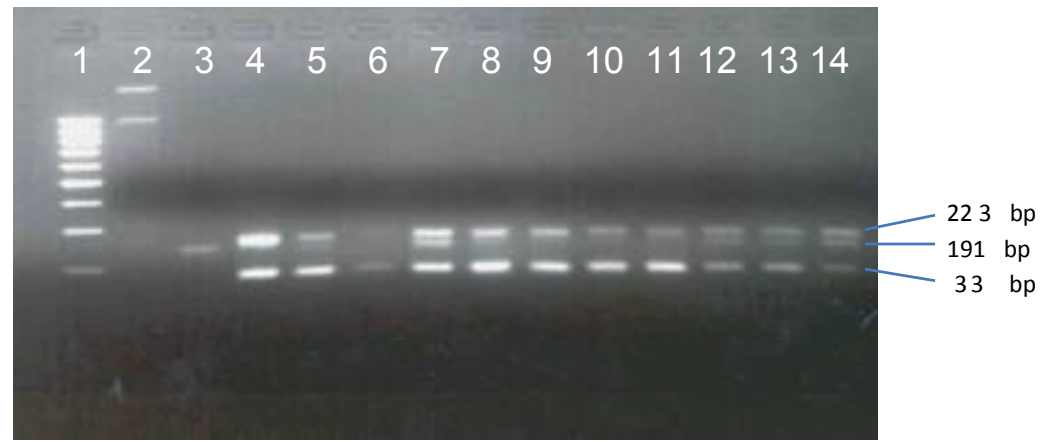

Figure 3: Screen of CHATR clones with I-Scel site at Eco47III. Lane 1-molecular weight marker, 2-substrate cut by I-Scel endonuclease, 3-pTK-UAS Sce-Eco47III (uncut), 4-pTK-UAS Sce-Eco47III (cut), 5-14 Clones E9-E18 (cut). The substrate is 223 bp and products 191 and 33 bp respectively.

and digested product detected on a $2 \%$ agarose gel. According to Figure 3 , the best results with regard to the active and inactive allele of TK1 gene, prompted us to select Eco47III clone\# 18 (shown in lane 14 of Figure 3 ) as the desired cell model and thus named E18.

\section{Characterization of E18 cell line}

We then extracted the whole cell DNA from TK6 (parent cell line without I-Scel site) and E18 (modified cell line with I-Scel insert) and ran an amplified 275 base pair product of intron 2 on a $2 \%$ agarose gel (Figure 4a) the band of interest in E18 was slightly heavier than TK6 suggesting that the I-Sce1 insert was intact. We then amplified a bigger fragment of intron 2 (700 base pair) and digested it with I-Sce1 restriction enzyme to confirm the presence of I-Scel site (Figure 4b). Since pTKUAS vector was used originally to construct the E18 cell line, we amplified the 700 base pair sequence within the ECOR47III site in the thymidine kinase locus (1441-2077 bp) and sequenced the product (at Colorado State University's Proteomics and metabolomics facility) to locate the I-Sce1 restriction sequence (TAGGGATAA ${ }^{\vee}$ CAGGGTAAT).
The primers used were: (F 1397> 5'-CGC CTC CAC CCA GCT AAT-3', R $<5$ ' AGT GGG GAA GGC AGA AGC-3'). The PCR product from E18 cells and the targeting vector was 700 base pair long.

\section{DNA sequencing of I-Scel site in intron 2 of the TK1 gene}

A 700 base pair (bp) product of intron 2 was amplified using the primers mentioned earlier and electrophoresed on a $2 \%$ agarose gel. The 700 bp band was gel purified using the Qiagen kit and DNA sequenced for locating the I-Scel site. The first 192 nucleotide bases (of E18 PCR product) were analyzed for BLAST human sequence and identified to be the human thymidine kinase gene located on chromosome 17 . This query confirmed that the E18 cell line did in fact have an I-Sce1 site in the thymidine kinase locus and since the cell line was constructed in 2006 there was reason to believe that the transfection was stable.

\section{Transfection efficiency determination}

When transfection efficiency (TE) was calculated using the formula described in materials and method section, a maximum average TE of $54 \%$ 
Citation: Nasir J (2017) Use of E18 Cell Model to Quantify DNA Strand Break Associated Bystander Effect (DSB-ABE). J Carcinogene Mutagene 8: 295. doi: $10.4172 / 2157-2518.1000295$

at $5 \mathrm{~h}$ could be achieved. The green signal could be detected for up to $15 \mathrm{~h}$ post-electroporation as shown in (Figure $5 \mathrm{c}$ ). When transfection efficiency was calculated for lipofection a TE of $40 \%$ could be achieved at $5 \mathrm{~h}$ but the maximum was achieved at $10 \mathrm{~h}$ time point (Figure 6a). Upon comparison of these results to the bystander mutation fraction due to electroporation of I-Sce1 vector into E18 cells, it appeared that lipofection was more mutagenic and resulted in higher cell mortality than electroporation (data not shown). This indicated that lipofectamine based delivery system was not suitable for these experiments. The one way ANOVA comparison of means gave a p-value of 0.0049 , however the TE at 5 and $10 \mathrm{~h}$ was


Figure 4: a) Shows I-Sce1 site in E18 cells A, B and C (lanes 4,5,6). Notice that the band of interest in E18 cells and the Vector (lane 2) is slightly heavier than the TK6 band since TK6 cell line does not have the I-Sce1 site. b) The 285 base pair PCR product shown in figure 4 was cleaved with 25 units of I-Sce1 enzyme. TK6 is a control cell line that lacks the I-Sce 1 site. The digested product shows up at approximately 260 bp while the undigested band is at 285 . Undigested and digested product of I-Sce1 restriction site in vector (lanes 2, 3), TK6 $(4,5)$, E18 A $(6,7)$ and E18 B $(8,9)$.

\section{Panel A (Control)}

0 Hour

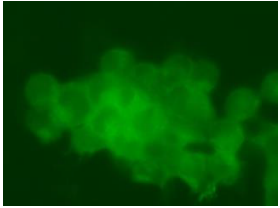

5 Hour

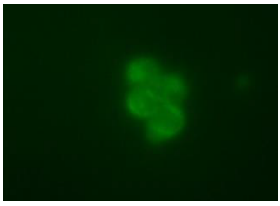

10 Hour

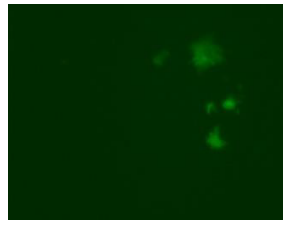

15 Hour

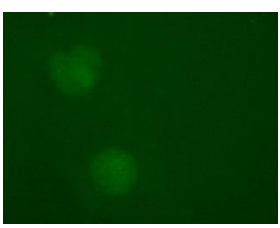

$\mathrm{B}$ (DAPI)

0 Hour



5hours

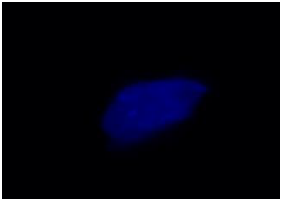

10 hours

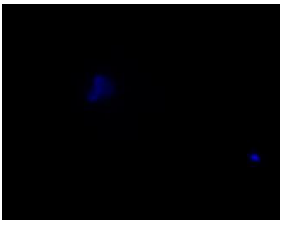

15 hours

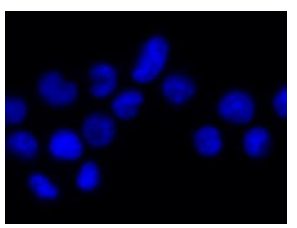

C (FITC)

0 Hour



5 hours

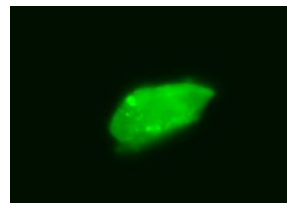

10hours



15 hours

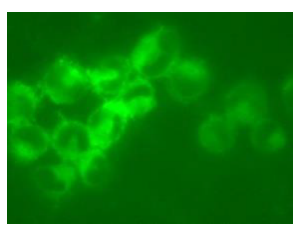

Figure 5: Panel A shows the control cells that were not transfected with experimental plasmid pAdTrack CMV I-Sce1. Panel B shows I-Sce1 transfected cells at 0,5 10 or $15 \mathrm{~h}$ after electroporation using the DAPI filter. Panel C shows the same field of view as in Panel B but using FITC filter at $0,5,10$ and $15 \mathrm{~h}$. 

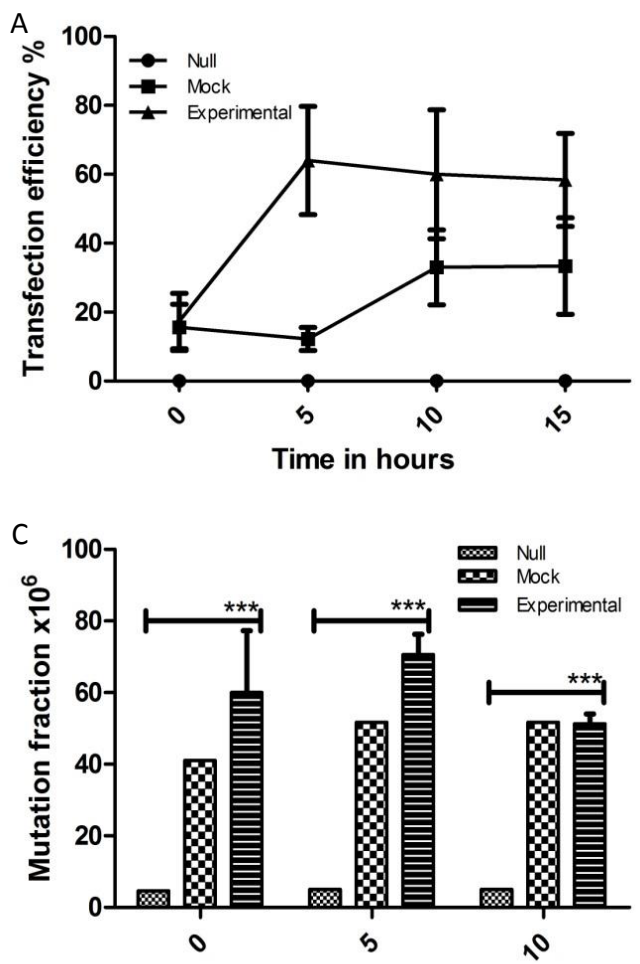

Time in hours
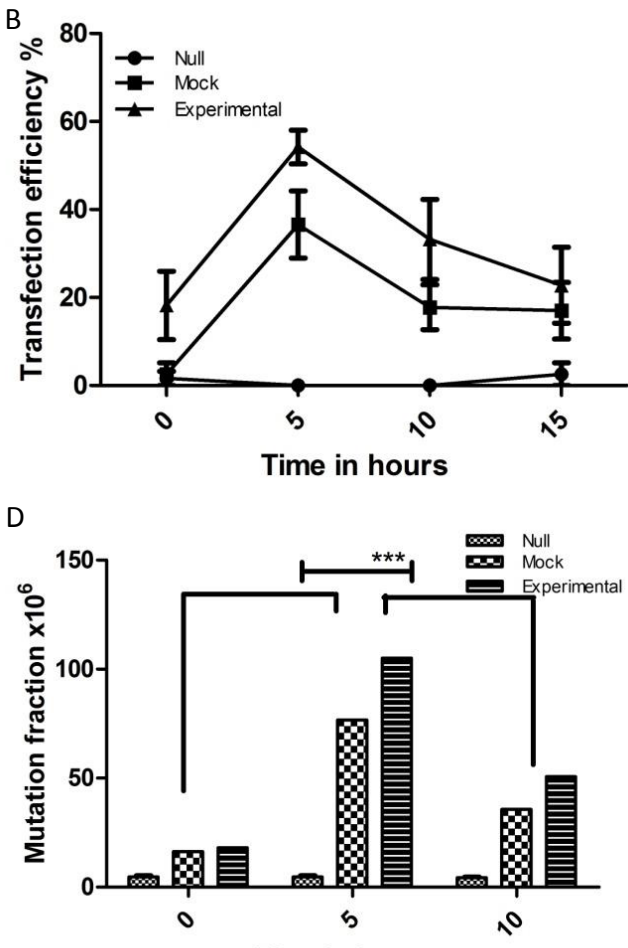

Time in hours

Figure 6: Transfection efficiency in percentage (TE) calculated at 0,5, 10 and $15 \mathrm{~h}$. a) Lipofectamine based transfection efficiency calculated with either no plasmid (Null), or control plasmid pAdTrack CMV (Mock) or experimental plasmid pAdTrack CMV I-Sce1. TE is plotted for the number of positively transfected green fluorescent cells as a percentage on the Y-axis ( $p$-value is 0.0049 ). b) same experimental set up as in (6a) but TE calculated for electroporation. TE as percentage measure of fluorescing green cells ( $p$-value=0.0100). All observations based on up to five random fields of view observed under $100 X$ magnification using FITC channel. Graphs plotted with SEM. c) the direct mutation fraction (MF) induced by transfection of experimental plasmid into the E18 cells and quantifying the direct effect of plasmid transfection. Various time points 0,5 and $10 \mathrm{~h}$ are not significantly different. d) the bystander mutation fraction (MF) induced by transfection of experimental plasmid

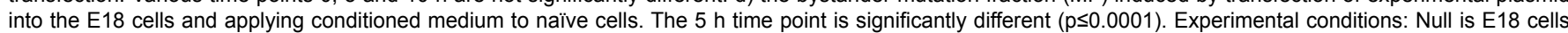
plated for background, Mock represents the E18 cells with pAdTrackCMV I-Sce1 but no transfection and plated for MF, Experimental represents E18 cells transfected with pAdTrackCMV I-Sce1 and plated for direct MF or bystander MF. Averages of three experiments plotted with SEM (*** highly significant).

similar. A similar analysis done with electroporation showed that $5 \mathrm{~h}$ time point gave the highest TE of 54\% (Figure $6 \mathrm{~b}$ ). A comparison of means produced a significant $\mathrm{p}$ value of 0.0100 . Hence it was logical to conclude that lipofectamine based transfection system did not produce sufficient bystander signal in $5 \mathrm{~h}$ to cause an increase in the naïve bystander cells. This could have been due to the high cell mortality associated with the toxic effect of transfection reagent.

DNA strand break associated bystander effect (DSB-ABE) due to transfection of I-Sce1 plasmid in E18 cells. In an attempt to investigate if radiation induced DNA damage is the only source of bystander signal synthesis, we used E18 cells to induce DNA damage in a radiation-independent manner. We calculated both directly induced mutation fraction (DMF) in Figure $6 \mathrm{c}$ as well as the bystander mutation fraction (BMF) at 0,5 and 10 hour time points. For BMF we transferred the medium from directly targeted cells to naïve cells at 0,5 and $10 \mathrm{~h}$ after electroporation using either E18 cells electroporated (Mock) or pAdTrackCMV I-Sce1 as the experimental plasmid electroporated into E18 cells (Figure 6d). It was clear that electroporation was also inducing some DNA damage and thus the 3 fold bystander MF increase (Figure $6 \mathrm{~d}$ ). The damage caused by I-Sce plasmid was about 6 fold compared to the control but almost 1-2 fold compared to mock at $5 \mathrm{~h}$ time point.
A two way ANOVA test analysis of three replicate experiments using pAdTrackCMV I-Scel compared to the background at 0,5 and $10 \mathrm{~h}$ indicated that DMF was not significantly different at various time points but for BMF it was significantly different $p \leq 0.0001$ at $5 \mathrm{~h}$ compared to $0 \mathrm{~h}$ or $10 \mathrm{~h}$ respectively. It was not clear from these experiments if electroporation or the experimental plasmid could have been the possible cause of increased BMF.

\section{Discussion}

E18 cell line was derived from TK6 lymphoblasts and was modified only in intron 2 (728 to $2359 \mathrm{bp}$ ) of the TK1 locus which flanks chromosome 17q23.2-q25.3. We successfully used the targeting vector pTK-UAS to incorporate the Eco 47 III site and later introduced an 18 base I-Scel sequence into the vector at the Eco47III site. The vector was identified to have inserted the desired Eco47III site along with the I-Sce1 sequence between 1441-2077 base pairs of intron 2 as revealed through DNA sequencing. Four vectors were used for troubleshooting as already mentioned in the results section but best results were obtained from clone \#18 that was targeted with pTK-UAS-Eco47III. Hence we named the cell line as E18.

We analyzed the Eco 47III and BsrG1 digested DNA products from all the clones and gel electrophoresis (Figure 2) that helped to identify in lanes 11 and 19 that two clones with Eco47III and BsrG1 
Citation: Nasir J (2017) Use of E18 Cell Model to Quantify DNA Strand Break Associated Bystander Effect (DSB-ABE). J Carcinogene Mutagene 8: 295. doi: 10.4172/2157-2518.1000295

sites respectively carried the I-Sce1 sequence. We therefore narrowed down our search to Eco47III clones and BsrG1 clones.

It was important to cut down the background mutations in the cell populations and screen for new mutants that carried the I-Scel sequence in intron 2 of the TK1 gene. Hence these clones were treated with CHAT for $48 \mathrm{~h}$ and plated. The CHAT resistant clones were selected and their DNA analyzed for the presence of active allele TK1 and the inactive allele of TK1. Following digestion of the PCR amplified product (223 bp) with I-Sce1 enzyme amongst all screened clones we recognized clone \#18 in lane 14 of Figure 3 to have all the desired characteristics intact.

A 700 base pair primer was designed to confirm the presence of I-Sce 1 site and locate the exact position. First we amplified a 275 base pair PCR product of E18 cells and compared it to the TK6 product (Figures $4 \mathrm{a}$ and $\mathrm{b}$ ). This showed the presence of slightly heavier bands in E18 cell line (A, B and C, in lanes 4, 5 and 6 respectively of Figure 4a). These E18 bands were from the same cell line cultured in different flasks. The heavy bands compared to TK6 indicated the presence of Eco47III. We then went on to amplify a much bigger fragment of DNA (700 base pairs) to map and locate the I-Sce1 site within the Eco 47III site (Figure $4 \mathrm{~b}$ ). The digested and undigested DNA products were electrophoresed on a $2 \%$ gel. Later we gel purified the 700 base pair product and sequenced it. DNA sequencing of E18 PCR product helped us to locate the I-Scel site at position 1692-1709 of the TK1 gene.

Having confirmed the stable transfection of I-Sce1 into TX528 cell line and characterized the new E18 cell line, we used pAdTrackCMV I-Sce1 for exogenous expression of the restriction enzyme and employed the green fluorescent protein (GFP) marker of the plasmid to calculate the transfection efficiency (Figures 5a-c) and used DAPI as the counter stain. We scored green fluorescing cells as positive for having received the I-Scel exogenous transcript, which synthesized the rare cutting restriction enzyme in the host cell and produced one double strand break at the I-Sce1 insert in intron 2 of the TK1 gene. Five random parts of the slides were scored at 5,10 and $15 \mathrm{~h}$ post-transfection and highest TE was achieved with electroporation at $5 \mathrm{~h}$ while with lipofection a similar TE could be achieved at $10 \mathrm{~h}$ (Figures $6 \mathrm{a}$ and $\mathrm{b}$ ). The control plasmid used was pAdTrack CMV without the I-Sce1. Lipofection appeared to be a good delivery system until we compared the cell mortality due to two systems. With electroporation we observed $2-3 \%$ mortality while lipofection induced up to $40 \%$ mortality (data not shown). Due to the toxic effect of lipofection reagent we report that electroporation is a comparatively better means of transfection for E18 lymphoblasts.

To show the efficacy of this cell system we measured the mutation fraction due to double strand breaks induced by the electroporation of I-Scel plasmid. In Figures $6 \mathrm{c}$ and $\mathrm{d}$ the DNA double strand breaks induced by the exogenous expression of I-Sce1 were measured in terms of increased DMF or transferring the conditioned medium to naïve cells and inducing bystander mutation fraction BMF. The mutation assay experiments measured mutation fraction as an indirect measure of double strand breaks (dsb) since they are a major contributor to the overall mutation pool.

For over two decades, since bystander effect was first reported by Nagasawa et al. [6] it has been associated with low dose ionizing radiations. Most investigators have reported bystander effect as a byproduct of targeted radiation, observed in non-targeted cells, and thus referred to as radiation induced bystander effect (RIBE) [14,15]. However it was argued by one team of investigators [14] that for bystander effect DNA damage is not essential and that cytoplasmic targets could also produce the same effect. In this recently discovered phenomenon, many questions remain unanswered but we wanted to find out if radiation independent DNA damage could also release the bystander signal.

Hence we used the cell model E18 to transfect it with pAdTrack CMV I-Sce1, induce radiation independent single DNA strand break and transfer the medium to naïve cells. In (Figures $6 c$ and $d$ ) we demonstrate that when conditioned medium was transferred from directly transfected cells to naïve cells at 0,5 and $10 \mathrm{~h}$ the BMF could be significantly increased compared to the background. At $5 \mathrm{~h}$ the $\mathrm{p}$-value measured with the two way ANOVA (and Bonferroni's post-test) for increased bystander mutation fraction due to the experimental plasmid pAdTrackCMV I-Sce 1 at $5 \mathrm{~h}$ was $<0.001$, which was highly significant.

Based on our current findings we concluded that DNA damage, either due to or without radiation targeting can potentially produce the bystander effect. This conclusion, however, does not negate the argument raised by other investigators that cytoplasmic targets within the cell have the ability to release a bystander signal, rather it suggests that radiation-independent damage of DNA is another source of bystander effect.

\section{Acknowledgments}

The author appreciates the valuable work of Wei Zhou and Kelle Phelps in the construction of E18 cells. For the provision of lab space and resources generously provided by Howard Liber and for the provision of PAdTrackCMV I-Sce1 plasmid provided by Jac Nickoloff, the author acknowledges their interest. The author also recognizes the useful feedback and insight provided by Susan Bailey (Department of environmental and radiological health sciences, Colorado State University, Fort Collins, Colorado) and James Bamburg (Department of Biochemistry, Colorado State University, Fort Collins, Colorado).

\section{References}

1. Mitelman F (2000) Recurrent chromosome aberrations in cancer. Mutat Res 462: 247-53.

2. Gullotta F, De Marinis E, Ascenzi P, di Masi A (2010) Targeting the DNA double strand breaks repair for cancer therapy. Curr Med Chem 17: 2017-2048.

3. Khanna KK, Jackson SP (2001) DNA double strand breaks: signaling, repair and the cancer connection. Nat Genet 27: 247-254.

4. Powell SN, Bindra RS (2009) Targeting the DNA damage response for cancer therapy. DNA Repair (Amst) 8: 1153-1165

5. Hosoya N, Miyagawa K (2014) Targeting DNA damage response in cancer therapy. Cancer Sci 105: 370-388.

6. Nagasawa H, Little JB (1992) Induction of sister chromatid exchanges by extremely low doses of a-particles. Cancer Res 52: 6394-6396.

7. Stenerlöw B (2006) Radiation-induced bystander effects. Acta Oncol 45: 373 374

8. Mothersill C, Seymour CB (2004) Radiation-induced bystander effects-implications for cancer. Nature Reviews Cancer 4: 158-164.

9. Seymour CB, Mothersill C, Alper T (1986) High yields of lethal mutations in somatic mammalian cells that survive ionizing radiation. Int J Radiat Biol Relat Stud Phys Chem Med 50: 167-179.

10. Morgan WF, Hartmann A, Limoli CL, Nagar S, Ponnaiya B (2002) Bystander effects in radiation-induced genomic instability. Mutation Research 504: 91100.

11. O'Reilly S, Mothersill C, Seymour CB (1994) Postirradiation Expression of Lethal Mutations in an Immortalized Human Keratinocyte Cell Line. International J Radiation Bio 66: 77-83.

12. Hagan $M$, Yacoub A, Dent $P$ (2004) lonizing radiation causes a dose-dependen release of transforming growth factor alpha in vitro from irradiated xenografts and during palliative treatment of hormone-refractory prostate carcinoma. Clin Cancer Res 10: 5724-5731. 
Citation: Nasir J (2017) Use of E18 Cell Model to Quantify DNA Strand Break Associated Bystander Effect (DSB-ABE). J Carcinogene Mutagene 8: 295. doi: $10.4172 / 2157-2518.1000295$

13. Littlefield JW (1966) The periodic synthesis of thymidine kinase in mouse fibroblasts. Biochem Biophys Acta 114: 398-403.

14. Prise KM, Folkard M, Kuosaite V, Tartier L, Zyuzikov N, et al. (2006) What role for DNA damage and repair in the bystander response? Mutat Res 597: 1-4.

15. Hei TK (2006) Cyclooxygenase-2 as a signaling molecule in radiation-induced bystander effect. Mol Carcinog 45: 455-460.

16. Dent P, Yacoub A, Contessa J, Caron R, Amorino G, et al. (2003) Stress and radiation-induced activation of multiple intracellular signaling pathways. Radiat Res 159: 283-300.

17. Jamali M, Trott KR (1996) Persistent increase in the rates of apoptosis and dicentric chromosomes in surviving V79 cells after X-irradiation. International J Radiation Biol 70: 705-709.

18. Maeda J, Yurkon CR, Fujii Y, Fujisawa H, Kato S, et al. (2015) Solution Radioactivated by Hadron Radiation Can Increase Sister Chromatid Exchanges. PLoS ONE 10: e0144619.

19. Azzam El, de Toledo SM, Douglas RS, Little JB (2002) Oxidative Metabolism Modulates Signal Transduction and Micronucleus Formation in Bystander Cells from a-Particle-irradiated Normal Human Fibroblast Cultures. Cancer Res 62 5436-542.

20. Prise KM, Schettino G, Folkard M, Held KD (2005) New insights on cell death from radiation exposure. Lancet Oncol 6: 520-528.

21. Asur RS, Thomas RA, Tucker JD (2009) Chemical induction of the bystande effect in normal human lymphoblastoid cells. Mutation Research/Genetic Toxicology and Environmental Mutagenesis 676: 11-16

22. Dahle J, Angell-Petersen E, Steen HB, Moan J (2001) Bystander effects in cell death induced by photodynamic treatment UVA radiation and inhibitors of ATP synthesis. Photochem Photobiol 73: 378-387.

23. Lyng FM, Seymour CB, Mothersill C (2006) The involvement of calcium and MAP kinase signaling pathways in the production of radiation-induced bystander effects. Radiat Res 165: 400-409.

24. Choulika A, Perrin A, Dujon B, Nicolas JF (1995) Induction of homologous recombination in mammalian chromosomes by using the I-Scel system of Saccharomyces cerevisiae. Mol Cell Biol 15: 1968-1973.

25. Bellaiche Y, Mogila V, Perrimon N (1999) I-Scel endonuclease, a new tool for studying DNA double-strand break repair mechanisms in Drosophila. Genetics 152: $1037-1044$

26. Shao C, Folkard M, Michael BD, Prise KM (2004) Targeted cytoplasmic irradiation induces bystander responses. Proc Natl Acad Sci U S A 101: 1349513500.
27. Honma M, Izumi M, Sakuraba M, Tadokoro S, Sakamoto H, et al. (2003) Deletion, rearrangement, and gene conversion; genetic consequences of chromosomal double-strand breaks in human cells. Environ Mol Mutagen 42: 288-298.

28. Honma M, Sakuraba M, Koizumi T, Takashima Y, Sakamoto H, et al. (2007) Non-homologous end-joining for repairing I-Scel-induced DNA double strand breaks in human cells. DNA Repair (Amst) 6: 781-788.

29. Suzuki T, Yasui M, Honma M (2016) Mutator Phenotype and DNA DoubleStrand Break Repair in BLM Helicase-Deficient Human Cells. Mole Cell Bio 36: 2877-2889.

30. Xia F, Amundson SA, Nickoloff JA, Liber HL (1994) Different capacities for recombination in closely related human lymphoblastoid cell lines with different mutational responses to X-irradiation. Mol Cell Biol 14: 5850-5857.

31. Amundson SA, Liber HL (1992) A comparison of induced mutation at homologous alleles of the th locus in human cells. II. Molecular analysis of mutants. Mutation Research/Fundamental and Molecular Mechanisms of Mutagenesis 267: 89-95.

32. Lippert MJ, Chen Q, Liber HL (1998) Increased transcription decreases the spontaneous mutation rate at the thymidine kinase locus in human cells. Mutation Research 401: 1-10.

33. Giver CR, Nelson SL, Cha MY, Pongsaensook P, Grosovsky AJ (1995) Mutational spectrum of $\mathrm{X}$-ray induced tk- human cell mutants. Carcinogenesis 16: 267-275.

34. Windbichler N, Menichelli M, Papathanos PA, Thyme SB, Li H, et al. (2011) A synthetic homing endonuclease-based gene drive system in the human malaria mosquito. Nature 473: 212-215.

35. Liber HL, Thilly WG, (1982) Mutation assay at the thymidine kinase locus in diploid human lymphoblasts. Mutat Res 94: 467-485.

36. Furth EF, Thilly WG, Penman BW, Liber HL, Rand WM (1981) Quantitative assay for mutation in diploid human lymphoblasts using microtiter plates. Anal Biochem 110: 1-8.

37. Lyng FM, Seymour CB, Mothersill C (2000) Production of a signal by irradiated cells which lead to a response in unirradiated cells characteristic of initiation of apoptosis. Br J Cancer 83: 1223-1230.

38. Liber HL, Yandell DW, Little JB (1989) A comparison of mutation induction at the tk and hprt loci in human lymphoblastoid cells; quantitative differences are due to an additional class of mutations at the autosomal tk locus. Mutat Res 216: 9-17.

39. Hei TK, Zhou H, Ivanov, Hong, Lieberman, et al. (2008) Mechanism of radiationinduced bystander effects: a unifying model. J Pharm Pharmacol 60: 943-950. 